\title{
Response of unilateral spinal anaesthesia in elderly patients admitted to BMC \& Allied Teaching Hospital in District BANNU- KPK.
}

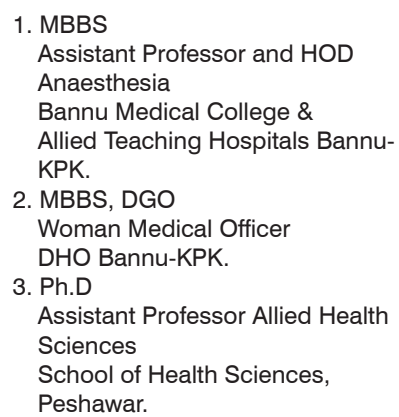

Correspondence Address:

Dr. Wasim Ahmad

Department of Allied Health Sciences School of Health Sciences, Peshawar. vazim4847@gmail.com

Article received on: 25/02/2020 Accepted for publication: 06/07/2020

\begin{abstract}
Sibghat Ullah', Rahila Begum ${ }^{2}$, Wasim Ahmad ${ }^{3}$
ABSTRACT... Objectives: The objective of this study was to investigate the possible restriction effects of unilateral spinal anaesthesia on sympathetic block to evade unwanted cardiac effects in elderly patients. Study Design: Cross section study. Setting: Department of Surgery, BMC Allied Teaching Hospitals District Bannu-KPK. Period: June 2018 to January 2020. Material \& Methods: In this study, 30 ASA III and ASA IV male adults having an age 55-65 and receiving lower limb surgery were included. The patients were given unilateral spinal anaesthesia (using $0.5 \%$ Bupivacaine). All the subjects were maintained in a lateral position having their operated side downwards and were kept in position for a period of 15 minutes. The assessment of the sensory and motor nerves was done, and hemodynamic changes were recorded following spinal anaesthesia. The monitoring was done for half an hour. Results: The observed hemodynamic effects in elderly patients were minimum which demonstrated the effectiveness of unilateral spinal anaesthesia in limiting the sympathetic block, evading the unwanted cardiac effects thus providing high cardiovascular stability. It was observed that the preparation time required for unilateral spinal anaesthesia was a bit longer as compared to conventional method. The technique also proved to be acceptable for patients with an elevated autonomy following surgical procedure and lesser urine retention. Conclusion: When unilateral spinal anaesthesia was administered in admitted patients using lower flow injection method and low volume, stable hemodynamic results were achieved. Patients were more satisfactory. Thus, unilateral spinal anaesthesia is effective in limiting the sympathetic block in old age patients.
\end{abstract}

Key words: Hemodynamic, Injection Speed, Sympathetic Block, Unilateral Spinal Anaesthesia.

Article Citation: Sibghat Ullah, Begum R, Ahmad W. Response of unilateral spinal anaesthesia in elderly patients admitted to BMC \& Allied Teaching Hospital in District BANNU-KPK. Professional Med J 2021; 28(2):187-191. https://doi.org/10.29309/TPMJ/2021.28.02.4593

\section{INTRODUCTION}

Unilateral spinal anaesthesia is an anaesthetic technique which is performed rapidly and is cost effective. Because of unavoidable bi-lateral sympathetic block that resulted due to spinal anaesthesia, the cardiac system of the human body is badly affected. Unilateral block results in affecting the sympathetic function on the body's one side. The advantages of one-sided spinal block are more as compared to bi-lateral block. For those with cardiovascular risks, unilateral spinal anaesthesia is suitable due to lack of hypotension. ${ }^{1}$ Due to an increased no of out-patients for surgical treatment, surgeons do not consider spinal anaesthesia suitable because of multiple reasons including post-op urinary retention, intra-op hypotension and most importantly, protracted post-op hospital stay. In unilateral spinal anaesthesia, motor functions restore quickly, lower degree of urinary retention and earlier discharge from hospital. The success of the technique is dependent on many factors including dosage and concentration of the anaesthetic agent, spinal needle shape, speed of the injection, patient's posture during and after injection etc.

Researchers have made serious efforts to explore the reasons and cardiovascular effects of spinal blockage (cardiovascular origin). More than 30\% of patients are suffered from hypotension due to spinal anaesthesia. ${ }^{2,3}$ To limit the sympathetic block due to conventional spinal anaesthesia is not possible at all. This sympathetic block 
surpasses the sensory block by 2-6 parts. ${ }^{4}$ A report demonstrated that as a result of conventional spinal anaesthesia, a decrease of $21 \%$ is observed in mean arterial blood pressure. ${ }^{5}$ More or less $3.7 \%$ increase of heartbeat is also observed as a result of anaesthesia to $\mathrm{T} 5 .{ }^{6}$ An increased bradycardia is reported when conventional spinal anaesthesia is administered to patients and this is because of its effects on dermatomes T1-T4 from where cardiac accelerator fibres are generated. Another effective technique is recommended by researchers to limit the unwanted sympathetic block. This alternative technique is known as unilateral spinal anaesthesia. ${ }^{7}$ The term is used when the block is associated only with operated side and its absence is observed at non-operated side. The cardiovascular side effects are reported to be lower when the surgery is performed at lower limb. The block remains advantageous and it facilitates the patient's earlier discharge as well.

The objective of this study was to assess the possible response and effectiveness of unilateral spinal anaesthesia in elderly patients admitted in BMC allied teaching hospitals.

\section{MATERIAL \& METHODS}

This study was conducted in BMC allied teaching hospitals in district Bannu from June 2018 to January 2020. Non-probability sampling technique (purposive sampling) was used for sampling. The study was carried out on $\mathbf{3 0}$ male adults that were decided for unilateral lower limb surgical treatment. The patients were ASA III and ASA IV (ASA III: patients having severe systematic disease that might or might not to associated for surgical procedure, ASA IV: patient with life threatening systematic disease including CAD etc.). All those patients that were contraindicated for local anaesthesia were excluded from the study. The ethical approval to conduct the study was granted by the ethical committee of Bannu medical college and allied hospitals, Bannu-KPK. The consent of all the patients was obtained prior to surgical treatment on a paper. The admitted patients were maintained NPO by mid night. No medicine was administered to the patients before the surgical treatment. All the patients were observed for any possible ischemic change, blood pressure, heartbeat and for oxygen overload. Prior to initiation of spinal blockage, IV canula was administered into the patients. The patients were placed on table in a lateral position with lower limb down. Figure-1 shows the position at which the patients were maintained. The lumber area was made aseptic and covered. L2-L3 or L3-L4 space was located and spinal anaesthesia was administered to the patients using a sprotte needle (25 G).

Hyperbaric bupivacaine $(0.5 \%)$ was injected within 20 seconds followed by intrathecal placement confirmation. Bupivacaine dose adjustment was done in accordance with the patient's height (1.1 $\mathrm{ml}$ for patients having height $<150 \mathrm{~cm}, 1.5 \mathrm{ml}$ for those having a height range between 150-175 and $1.8 \mathrm{ml}$ for patients more than $175 \mathrm{~cm})$. The lateral position of the patients was maintained for approximately 10min with surgical limb down. Following spinal anaesthesia, sensory block was monitored at every $5 \mathrm{~min}$ interval for half an hour. This was done using ice boxes. Similarly, lower limb's motor block was also measured in the same way using bromage scale. The patients were advised and monitored for rising the extended legs, flexing the knee, flexing the ankle etc with a rating $0-4(0=$ No paralysis, $1=$ extended leg rising inability, $2=$ flexing knee inability, $3=$ inability of dorsiflexion of feet with jiggle toes, $4=$ movement inability at all). The assessment of heart rate and blood pressure was done before, after and every 5 min during half an hr time period of spinal anaesthesia. The patients were sedate with midazolam IV injection at a dose 1-2mg. the total time taken for surgical procedure and any possible complications was monitored and noted. The patients were shifted to rooms after the operation. Upon stabilizing the hemodynamic status of the patients and their physical ability to walk, they were discharged from the hospital/ clinic.

The ethical approval for this study was taken from the "Institutional Ethics Committee" through letter no BMC/0022/2020.

The data was analysed using statistical programme SPSS. ANOVA was run for analysing heart rate, systolic and diastolic blood pressure 
individually. A $p$-value $<0.05$ was considered as significant.

\section{RESULTS}

Demographic data of the patients is shown in Table-1 below. A total of 30 adult male were selected for the study with ASAIII and IV. Their mean age was 61years and the average time of surgery was 50 minutes. Of total 30 patients, 20 were ASAIII and 10 were ASAIV patients.

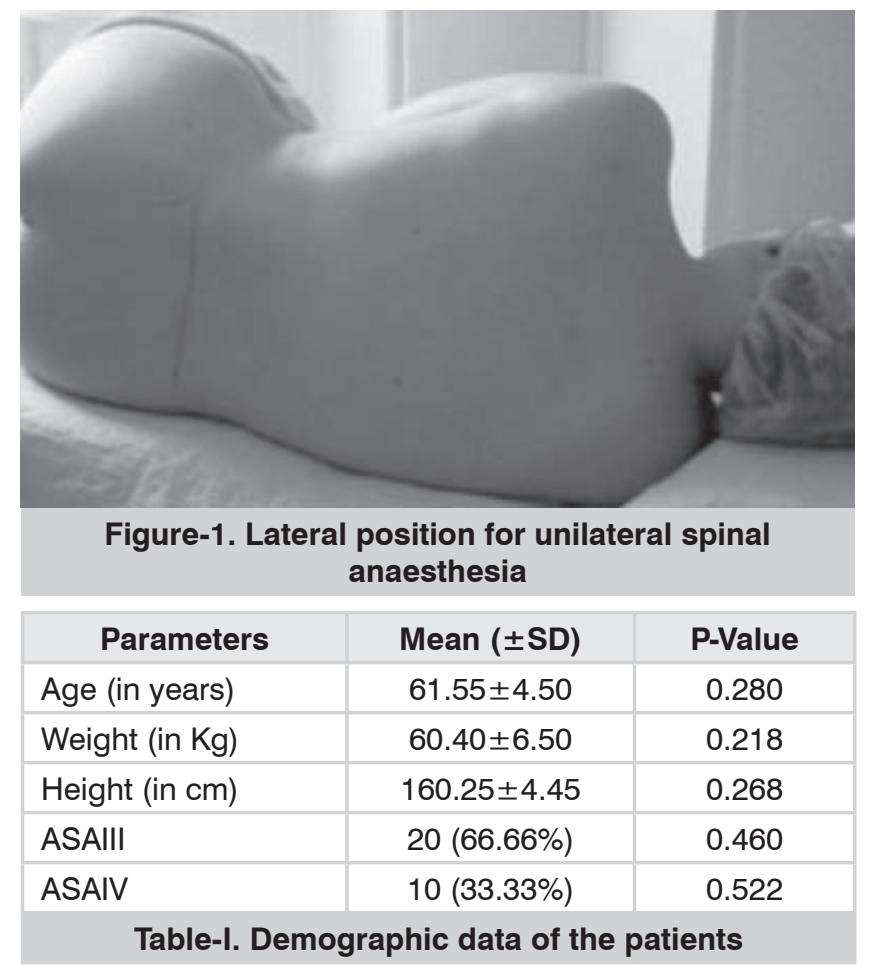

\section{Results of haemodynamic variables, sensory block and motor block assessment are explained in the following.}

\section{Haemodynamic Variable}

It was noted that systolic blood pressure was dropped from the base line just after spinal anaesthesia. The drop was observed after $5 \mathrm{~min}$ of spinal anaesthesia. After this drop, no momentous alteration in the blood pressure was observed until half an hr. the results are shown in Figure-2 below.

The diastolic blood pressure was dropped remarkably from the base line at $5 \mathrm{~min}$ following that, there was no remarkable decline until half an hr. The results are shown in Figure-3 below.
Graph of SBP vs Time

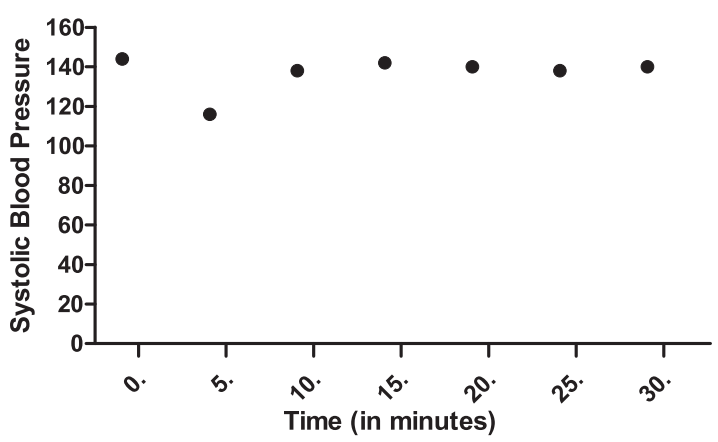

Figure-2. Change in systolic blood pressure with Time Change in DBP vs Time

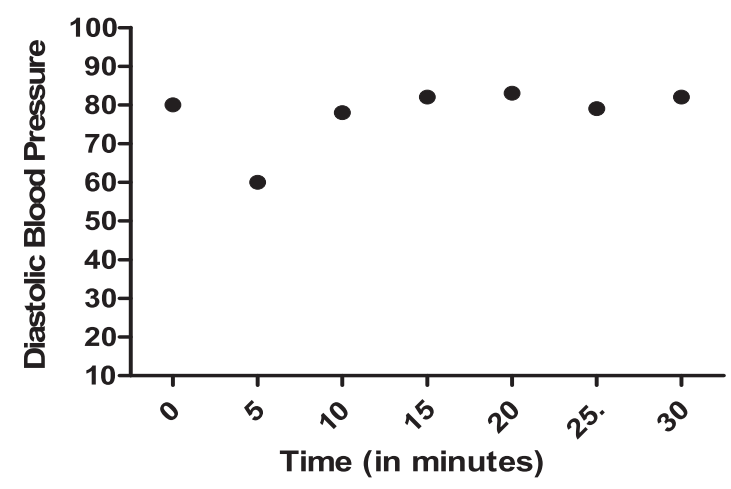

Figure-3: Change in systolic blood pressure with time

No statistical remarkable alteration was observed in heart rate until $15 \mathrm{~min}$ followed by spinal blockage. The heart rate was dropped from base line after 20min and no further drop was observed until half an hr next. The results are shown in figure 4 below.

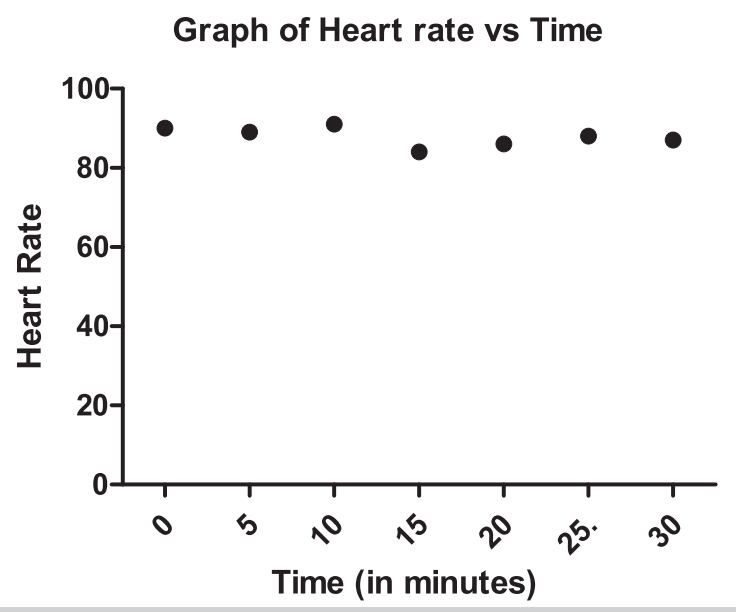

Figure-4. Change in heart rate with time 
Transient bradycardia (less than 55beats/ min) was observed only in two patients. The hypotension of 3 patients was rectified with 200mg Phenylephrine.

\section{Sensory Blockage}

The findings of the study revealed an elevated sensory level for the surgically operated limb at 10 min followed by no remarkable alteration until half an $\mathrm{hr}$. The blockage was augmented at 5 and $15 \mathrm{~min}$ for non-operated limb. No further increase was observed after this time period.

\section{Motor Blockage}

At $5 \mathrm{~min}$, the severity of paralysis for operated leg was 2.2 than non-operated leg on bromo scale. However, at a time more than $5 \mathrm{~min}$, the severity of operated leg was 86.0 time greater than nonoperated one. This shows the initial blockage of both legs but following $5 \mathrm{~min}$ time, non-operated leg motor nerves were no more blocked.

\section{DISCUSSION}

Conventional spinal anaesthesia results in $\mathrm{PAH}$ (precipitous arterial hypotension) because of higher sympathetic blockage which remains a common problem. The condition in more common with elderly patients. Reports are there which shows that in anaesthesia practice, the reduced injected quantity and more concentrated local anaesthetic hyperbaric solution cannot be produce block absolutely. In our clinical practice, we are using unilateral spinal anaesthesia in a reduced quantity. We are not using the increased concentration of the drug. This resulted in undesirable effects avoidance. Our results showed that the use of $0.5 \%$ hyperbaric bupivacaine solution in reduced amount for unilateral spinal anaesthesia, the sympathetic blockage is restricted effectively. This results in prevention of the hemodynamic effects that are undesirable in elderly patients..$^{7-9}$ Our study showed a correlation of ice boxes with the function of $C$ fibers. ${ }^{10}$ The study showed an achievement in sensory loss in operated limb which was found to be higher than non-operated limb. The loss of sensation was found in non-operated limb in a lower level.
It is obvious from this study that even when using a small volume of the drug, we cannot evade some spill over effects on the non-operative limb, though hyperbaric local anaesthetic solution in abridged quantity, bounds the spread of drug to the non-operated side. The clinical relevance of these motor and sensory level alters on non-operated limb may be questioned. Haemodynamic alterations assessed in our patients were very minor and could be overlooked, as these alterations happened in the initial $5 \mathrm{~min}$, later on patient continued to be stable haemodynamically. Numerous reports ${ }^{11,15}$ have exposed the practicality of unilateral block in ASA I and II patients, however in our study, only elderly patients were involved. The expected small hemodynamic alterations in unilateral blockage might be more pertinent in elderly and chronically ill patients and additional controlled studies should be done to assess the practicality of unilateral spinal anaesthesia in elderly patients.

\section{CONCLUSION}

Unilateral spinal anaesthesia is effective in limiting the sympathetic block with cardiac stability in elderly patients. When unilateral spinal anaesthesia is administered in admitted patients using lower flow injection method and low volume, stable hemodynamic results are achieved. Patients satisfaction is more as compared to ordinary method. Greater recovery is also achieved in this case.

\section{Copyright $\odot 06$ July, 2020.}

\section{REFERENCES}

1. Apaydın Y, Erk G, Sacan O, Tiryaki C, Taspinar V. Characteristics of unilateral spinal anesthesia at different speeds of intrathecal injection. Journal of anesthesia. 2011 Jun 1; 25(3):380-5.

2. Enk D, Prien T, Van Aken H, Mertes N, Meyer J, Brüssel $T$. Success rate of unilateral spinal anesthesia is dependent on injection flow. Regional anesthesia and pain medicine. 2001 Sep 1; 26(5):420-7.

3. Fanelli G, Borghi B, Casati A, Bertini L, Montebugnoli $M$, Torri $G$. Unilateral bupivacaine spinal anesthesia for outpatient knee arthroscopy. Canadian Journal of Anesthesia. 2000 Aug 1; 47(8):746-51. 
4. Kuusniemi KS, Pihlajamäki KK, Pitkänen MT. A low dose of plain or hyperbaric bupivacaine for unilateral spinal anesthesia. Regional Anesthesia \& Pain Medicine. 2000 Nov 1; 25(6):605-10.

5. Kelly D, McCoy D, Wall C. Hemodynamic changes induced by equivalent levels of sympathetic denervation during bilateral or unilateral spinal anesthesia. Anesth Analg. 1996; 82:S223.

6. Casati A, Moizo E, Marchetti C, Vinciguerra F. A prospective, randomized, double-blind comparison of unilateral spinal anesthesia with hyperbaric bupivacaine, ropivacaine, or levobupivacaine for inguinal herniorrhaphy. Anesthesia \& Analgesia. 2004 Nov 1; 99(5):1387-92.

7. Valanne JV, Korhonen AM, Jokela RM, Ravaska P, Korttila KK. Selective spinal anesthesia: A comparison of hyperbaric bupivacaine $4 \mathrm{mg}$ versus $6 \mathrm{mg}$ for outpatient knee arthroscopy. Anesthesia \& Analgesia. 2001 Dec 1; 93(6):1377-9.

8. NIEMI L. Effects of intrathecal clonidine on duration of bupivacaine spinal anaesthesia, haemodynamics, and postoperative analgesia in patients undergoing knee arthroscopy. Acta anaesthesiologica scandinavica. 1994 Oct; 38(7):724-8.

9. Merivirta $R$, Kuusniemi $K$, Jaakkola $P$, Pihlajamäki $K$, Pitkänen $M$. Unilateral spinal anaesthesia for outpatient surgery: A comparison between hyperbaric bupivacaine and bupivacaine-clonidine combination. Acta anaesthesiologica scandinavica. 2009 Jul; 53(6):788-93.
10. Casati A, Fanelli G, Aldegheri G, Colnaghi E, Casaletti E, Cedrati V, Torri G. Frequency of hypotension during conventional or asymmetric hyperbaric spinal block. Regional Anesthesia and Pain Medicine. 1999 May 1; 24(3):214-9.

11. Imbelloni LE, Beato L, Cordeiro JA. Unilateral spinal anesthesia with low $0.5 \%$ hyperbaric bupivacaine dose. Revista brasileira de anestesiologia. 2004 Oct; 54(5):700-6.

12. Krobot R, BACAK KOCMAN IV, Premužić J. Unilateral spinal anaesthesia for varicose vein surgery: $A$ comparison of hyperbaric bupivacaine $7.5 \mathrm{mg}$ versus hyperbaric bupivacaine $5 \mathrm{mg}+$ fentanyl 25 $\boldsymbol{\mu g}$. Periodicum biologorum. 2009 Jun 15; $111(2): 293-7$.

13. Casati A, Fanelli G, Cappelleri G, Borghi B, Cedrati V, Torri G. Low dose hyperbaric bupivacaine for unilateral spinal anaesthesia. Canadian journal of anaesthesia. 1998 Sep 1; 45(9):850-4.

14. Kaya M, Oğuz S, Aslan K, Kadıoğulları N. A low-dose bupivacaine: A comparison of hyperbaric and hypobaric solutions for unilateral spinal anesthesia. Regional Anesthesia \& Pain Medicine. 2004 Jan 1; 29(1):17-22.

15. Kocman BI, KrobotR, Premuzic J, Vucelic N. Comparison of unilateral and bilateral spinal anesthesia with hyperbaric bupivacaine $7.5 \mathrm{mg}+$ fentanyl $25 \mu \mathrm{g}$ for inguinal hernia repair: 8AP2-6. European Journal of Anaesthesiology (EJA). 2010 Jun 12; 27(47):131.

\begin{tabular}{|c|c|c|c|}
\hline \multicolumn{4}{|c|}{ AUTHORSHIP AND CONTRIBUTION DECLARATION } \\
\hline Sr. \# & Author(s) Full Name & Contribution to the paper & Author(s) Signature \\
\hline 1 & Sibghat Ullah & 1st Author & \\
\hline 2 & Rahila Begum & 2nd Author & \\
\hline 3 & Wasim Ahmad & 3rd Author & \\
\hline
\end{tabular}

